\title{
Kinetic Spectrophotometric Method for Determination of Vanadium in Syrian Oil Using 1, 5-Diphenylcarbazide Reagent
}

\author{
${ }^{1}$ Issa Moustafa, ${ }^{2 *}$ Mouhammed Khateeb, ${ }^{3}$ Obaida Alhamed \\ ${ }^{1,3}$ Department of Chemistry, Faculty of Sciences, Al- Baath University Homs, Syria. \\ ${ }^{2}$ Department of Basic Sciences, Faculty of Mechanical and Electrical Engineering \\ Al-Baath University Homs, Syria. \\ *E-mail: drkhateeb2010@gmail.com, mkhateeb74@hotmail.com
}

Keywords: Diphenylcarbazide, Kinetic Spectrophotometry, Vanadium (V), Syrian Oil.

\begin{abstract}
New, sensitive, accurate and inexpensive kinetic spectrophotometric method was developed and validated for the determination of $\mathrm{V}(\mathrm{V})$ in crude oil and its heavy product. The method is based on the formation of colored complex between $\mathrm{V}(\mathrm{V})$ and 1, 5-diphenylcarbazide (DPCI). The method involves the reaction of $\mathrm{V}(\mathrm{V})$ with DPCI in presence of buffer solution of $\mathrm{pH}$ 6.8 to form colored complex with $\lambda_{\max }$ at $530 \mathrm{~nm}$. The fixed time method $(2000 \mathrm{Sec})$ was adopted for constructing the calibration curve. The linearity range was found to be $(2-12) \mathrm{mg} / \mathrm{L}$. The correlation coefficient was 0.9999 and the limit of detection was found to be $0.349 \mathrm{mg} / \mathrm{L}$. The method is feasible with the calibration equations obtained, which makes this method more applicable. Statistical treatment of the experimental results indicates that the method is precise, selective and accurate. The method was successfully applied for determination of V(V) in Syrian crude oil and its heavy product.
\end{abstract}

\section{1 - INTRODUCTION}

Diphenylcarbazide (DPCI) considers as one of the group of chemicals derived from hydrazine, used for determination of various metals in acid media. DPCI reacts with osmium to form a blue violet complex, which shows an absorption maximum at $560 \mathrm{~nm}$ [1]. Three different methods have been reported for determination of osmium in a weakly acid solution by using DPCI to form complex with ratio 1:1 (Os: DPCI) [2].

A new, quite, rapid, simple and selective voltammetric method has been described to determine $\mathrm{Cr}(\mathrm{VI})$, by using DPCI at $\mathrm{pH}$ between 1 and 2 to form-modified carbon paste electrode. [3], and flow injection analysis [4]. Many spectrophotometric studies to assay vanadium in various media were carried out[5-11].

Kinetic methods have certain advantages as selectivity and elimination of additive interferences, which affect direct spectrophotometric methods [12-15]. The literature is still poor in analytical assay methods based on kinetics for the determination of $\mathrm{V}(\mathrm{V})$ in oil forms, therefore, there is a need for another kinetic approach to estimate $V(V)$ in oil forms.

\section{2 - EXPERIMENTAL}

\subsection{Apparatus}

$\mathrm{pH}$ measurements were made with Sartorius PB-11 (USA) with combined glass $\mathrm{pH}$ electrode. Jasco V-530 UV-VIS spectrophotometer (Japan) with $1 \mathrm{~cm}$ quartz cells was used for all absorbance measurements under the following operating conditions: scan speed medium (400 $\mathrm{nm} / \mathrm{min}$ ), scan range $200-1100 \mathrm{~nm}$ and slit width $2 \mathrm{~nm}$. Spectra were automatically obtained by Jasco system software.

\subsection{Reagents and materials}

All materials and reagents were of analytical grade and solutions were prepared with doubly distilled water. 1,5-diphenylcarbazide (DPCI) was obtained from BDH (England). The purity of 
DPCI was $98.0 \%$, standard of V(V) was obtained from CHEM-LAB. Stock standard solution of $\mathrm{V}(\mathrm{V}) 1000 \mathrm{mg} / \mathrm{L}$ (Belgium), acetone was obtained from Panreac with purity $99.5 \%$, soduim hydroxide was obtained from POCH SA (Poland) with purity 99.0\%, Sulfuric acid was obtained from CHEM-LAB with purity $98 \%$. Stock standard solution of DPCI $\left(2.06 \times 10^{-2} \mathrm{M}\right)$ was prepared by dissolving $0.5 \mathrm{gr}$ of DPCI in $0.5 \mathrm{~mL}$ of $0.5 \mathrm{~N} \mathrm{H}_{2} \mathrm{SO}_{4}$ solution and diluting to $100 \mathrm{~mL}$ with acetone. Buffer solution pH 6.8 (Britton $1 \mathrm{M}$ ) boric acid $(1 \mathrm{M})$, acetic acid $(1 \mathrm{M})$ and phosphoric acid (1M) were prepared by dissolving $62.41 \mathrm{~mL}$ boric acid, $57.43 \mathrm{~mL}$ acetic acid and $67.42 \mathrm{~mL}$ phosphoric acid in $1000 \mathrm{~mL}$ water and adjusting to $\mathrm{pH} 6.8$.

\subsection{Procedure for fixed time method}

Aliquots of 2-12 mg/L of standard V(V) solution $(0.5-3.0 \mathrm{~mL}, 100 \mathrm{mg} / \mathrm{mL})$ were transferred into a series of $25 \mathrm{~mL}$ calibrated volumetric flasks. Then $6 \mathrm{~mL}$ of $2.0 \times 10^{-3} \mathrm{M}$ DPCI solution and $2.5 \mathrm{~mL}$ of buffer solution $(\mathrm{pH} 6.8)$ were added. The volume was made up to the mark with water and the absorbance was measured after $2000 \mathrm{Sec}$ at $530 \mathrm{~nm}$ against the reagent blank. Concentrations of $\mathrm{V}(\mathrm{V})$ in crude oil and its heavy product were determined from the calibration curve.

\subsection{Procedure for Oil forms}

Wet ashing method was used for preparation of the oil samples [16,17]. Three samples were mixed thoroughly (powdered in the case of coke sample). An amount corresponding to $10-50 \mathrm{~g}$ of samples were weighed, dissolved with $(10-20) \mathrm{mL}$ of $98 \% \mathrm{H}_{2} \mathrm{SO}_{4}$ solution. The samples were heated until the white fumes were stopped. The Samples are placed in ashtray at $500^{\circ} \mathrm{C}$ for 24-72 hour. Subsequently, the ash was dissolved with $\left(2 \mathrm{~mL}\right.$ of $98 \% \mathrm{H}_{2} \mathrm{SO}_{4}, 2 \mathrm{~mL}$ of $37 \% \mathrm{HCl}$ and $2 \mathrm{~mL}$ of $69 \% \mathrm{HNO}_{3}$ ). The samples solutions were heated until the white fumes were stopped and diluting to $100 \mathrm{~mL}$ with double distilled water. The resulting solution was used for analysis by the recommended procedures in the concentration range mentioned above.

\section{3 - RESULTS AND DISCUSSION}

\subsection{Absorption spectra}

$\mathrm{V}(\mathrm{V})$ was found to react with DPCI in an acid medium at $25^{\circ} \mathrm{C}$ producing an pink colored product which absorbs maximally at $530 \mathrm{~nm}$ as shown in Figure 1. The increase in the intensity of the color by time was used as a basis for a useful kinetic method for the determination of $V(V)$ in crude oil and its heavy product.

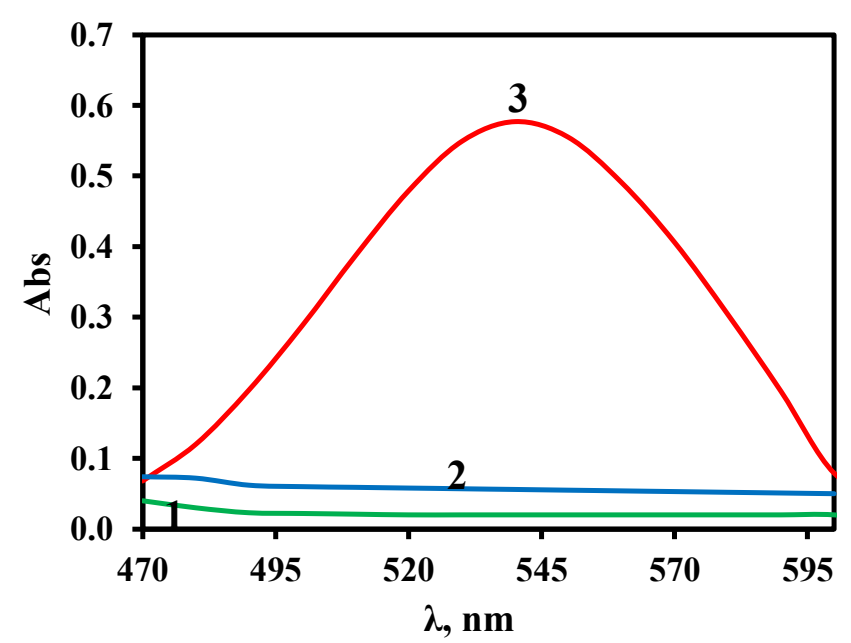

Figure 1. Absorption spectra of (1) V(V) solution (12 mg/L) against water, (2) reagent blank solution against water and (3) the reaction product of $\mathrm{C}_{\mathrm{V}(\mathrm{V})}=12 \mathrm{mg} / \mathrm{L}+6 \mathrm{~mL} \mathrm{DPCI}\left(2.0 \times 10^{-3} \mathrm{M}\right)$ $+2.5 \mathrm{~mL}$ of britton $1 \mathrm{M}$ in $25 \mathrm{~mL}$ final volume); reaction time: $60 \mathrm{~min}$. 


\subsection{Optimization of reaction conditions}

The spectrophotometric properties of the colored product as well as the different experimental parameters affecting the color development and its stability were studied and optimized by changing each variable in turn, while keeping all others constants. In all experiments, $\mathrm{V}(\mathrm{V})$ concentration was constant $12 \mathrm{mg} / \mathrm{L}$. The effect of Buffer solution (Britton $1 \mathrm{M}$ ) concentration on the reaction was studied over the range $2 \times 10^{-2}-14 \times 10^{-2} \mathrm{M}$, in the final concentration. The maximum absorbance was obtained at concentration of $10 \times 10^{-2} \mathrm{M}$ (when $2.5 \mathrm{~mL}$ of $1 \mathrm{M}$ Britton was added). The influence of DPCI was investigated between $2.0 \times 10^{-4}$ and $5.6 \times 10^{-4} \mathrm{M}$ in the final concentration $\left(6 \mathrm{~mL}\right.$ of $\left.2.0 \times 10^{3} \mathrm{M} \mathrm{DPCI}\right)$ was chosen for all subsequent experiments (Figure 2).

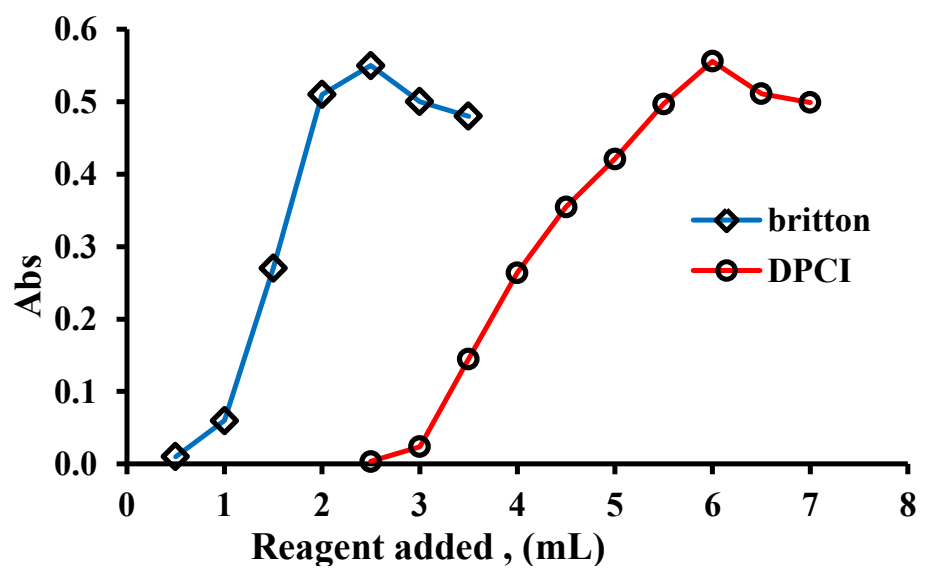

Figure 2. Effect of $1 \mathrm{M}$ britton and $2.0 \times 10^{-3} \mathrm{M}$ DPCI volume on the absorbance at $530 \mathrm{~nm}$ of reaction product of $12 \mathrm{mg} / \mathrm{L} \mathrm{V}(\mathrm{V})$ at $25^{\circ} \mathrm{C}$ in final volume of $25 \mathrm{~mL}$, time $60 \mathrm{~min}$.

\subsection{Quantitation methods}

As the intensity of the color increased at $530 \mathrm{~nm}$ with time (Figure 3) this was used as the basis for a useful kinetic method for the determination of $\mathrm{V}(\mathrm{V})$. The rate data, rate constant, fixed absorbance and fixed time methods $[18,19]$ were carried out and the most suitable analytical methods were chosen regarding the applicability, sensitivity, the values of the intercept and correlation coefficient (r).

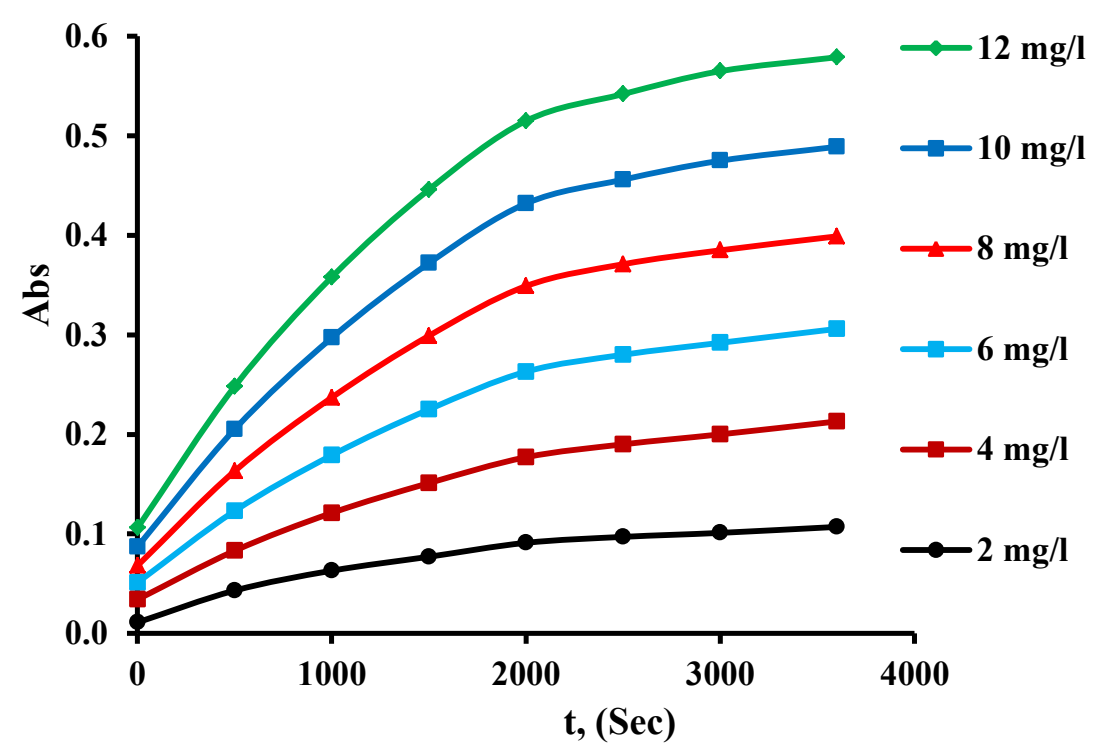

Figure 3. Absorbance-time curve for the reaction of $\mathrm{V}(\mathrm{V})$ with $\lambda_{\max }=530 \mathrm{~nm}: \mathrm{C}_{\mathrm{DPCl}}=4.8 \times 10^{-4} \mathrm{M}:$ DPCI $-\mathrm{pH}=6.8$ 


\subsubsection{Rate data method:}

The rate data of reaction would follow a pseudo order rate constant and obeyed the following rate equation:

$$
v=\frac{\Delta \mathrm{C}}{\Delta \mathrm{t}}=\frac{\Delta \mathrm{A}}{\Delta \mathrm{t}}=\dot{\mathrm{K}} \cdot \mathrm{C}^{\mathrm{n}}
$$

Where $v$ is the reaction rate, $\mathrm{A}$ is the absorbance, $\Delta \mathrm{A}=\mathrm{At}_{2}-\mathrm{At}_{1}, \mathrm{t}$ is the measuring time, $\Delta \mathrm{t}=\mathrm{t}_{2}-\mathrm{t}_{1}, \mathrm{k}^{\prime}$ is the pseudo order rate constant, $\mathrm{C}$ is the concentration of the $\mathrm{V}(\mathrm{V}) \mathrm{mol} / \mathrm{L}$ and $\mathrm{n}$ is the order of the reaction. A calibration curve was constructed by plotting the logarithm of the initial rate of reaction $(\log v)$ versus $\operatorname{logarithm}$ of $\mathrm{V}(\mathrm{V})$ concentration $(\log \mathrm{C})$, which showed a linear relationship over the concentration range of (2-12)mg/L (Figure 4).

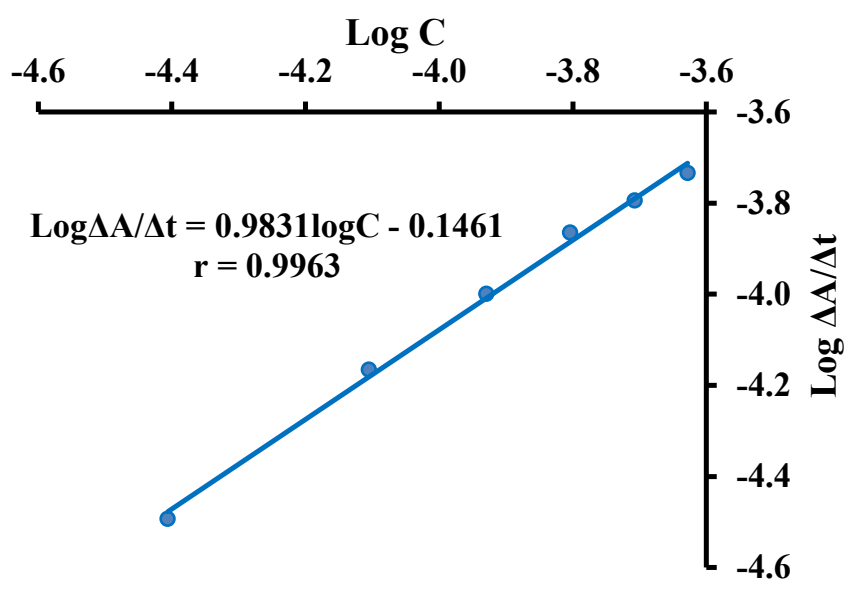

Figure 4. Calibration plot of logarithm rate of the reaction against logarithm molar concentration of $\mathrm{V}(\mathrm{V})$ for rate data method, $\left(\mathrm{t}_{1}=1000 ; \mathrm{t}_{2}=1250 \mathrm{Sec}\right)$.

The logarithmic form of the above equation is written as follows:

$\log v=\log \Delta \mathrm{A} / \Delta \mathrm{t}=\log \mathrm{k}^{\prime}+\mathrm{n} \log \mathrm{C}$

$$
\log v=\log \Delta \mathrm{A} / \Delta \mathrm{t}=0.9831 \log \mathrm{C}_{\mathrm{V}(\mathrm{V})}-0.1461 \quad(\mathrm{r}=0.9963)
$$

Thus, $\mathrm{k}^{\prime}=0.714 \mathrm{Sec}^{-1}$, and the reaction is the first order $(\mathrm{n}=0.9831)$ with respect to $\mathrm{V}(\mathrm{V})$ concentration.

\subsubsection{Rate constant method:}

The logarithm of the absorbance of reaction versus time for each concentration of $\mathrm{V}(\mathrm{V})$ which studied over the concentrtion rang of $2-12 \mathrm{mg} / \mathrm{L}$ was calculated. Graphs of log absorbance versus time for $\mathrm{V}(\mathrm{V})$ concentration in the range of $8-12 \mathrm{mg} / \mathrm{L}\left(1.570 \times 10^{-4}-2.355 \times 10^{-4}\right)$ were plotted and all appeared to be rectilinear. Pseudo order rate constant $\left(k^{\prime}\right)$ corresponding to different $\mathrm{V}(\mathrm{V})$ concentrations were calculated from the slopes multiplied by -2.303 and are presented in (Figure 5). Regression of $C$ versus $k^{\prime}$ gave the following equation:

$$
\mathrm{k}^{\prime}=0.2935 \mathrm{C}-0.00013 \quad(\mathrm{r}=0.7506) .
$$

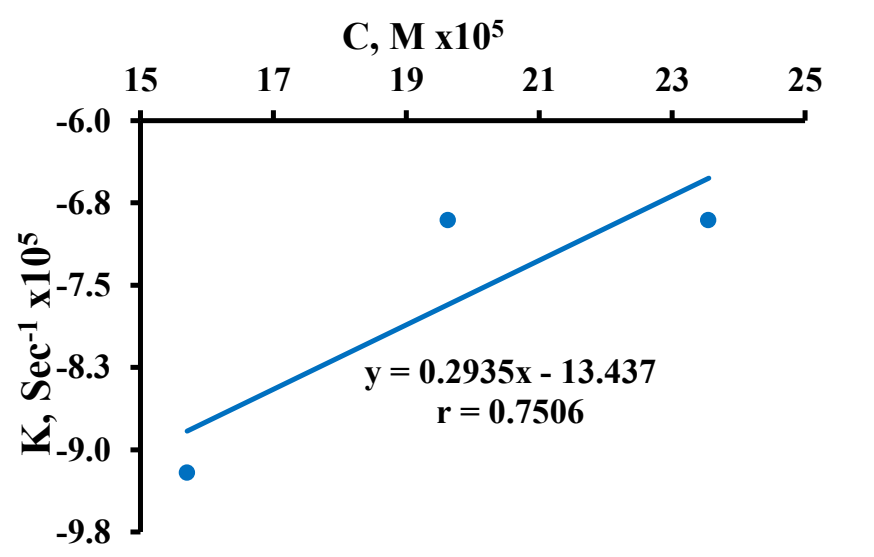

Figure 5. Calibration plot of $\mathrm{V}(\mathrm{V})$ for rate constant method. 


\subsubsection{Fixed absorbance method:}

Reaction rate data were recorded for different $\mathrm{V}(\mathrm{V})$ concentrations in the range $6-12 \mathrm{mg} / \mathrm{L}$ $\left(1.177 \times 10^{-4}-2.355 \times 10^{-4} \mathrm{M}\right)$. A preselected value of the absorbance 0.3 was fixed and the time was measured in the seconds. The reciprocal of time $(1 / \mathrm{t})$ versus the initial concentration of $\mathrm{V}(\mathrm{V})$ was plotted (Figure 6) and the following equation of calibration graph was obtained.

$$
1 / \mathrm{t}=9.4217 \mathrm{C}-0.00083911 \quad(\mathrm{r}=0.9956)
$$

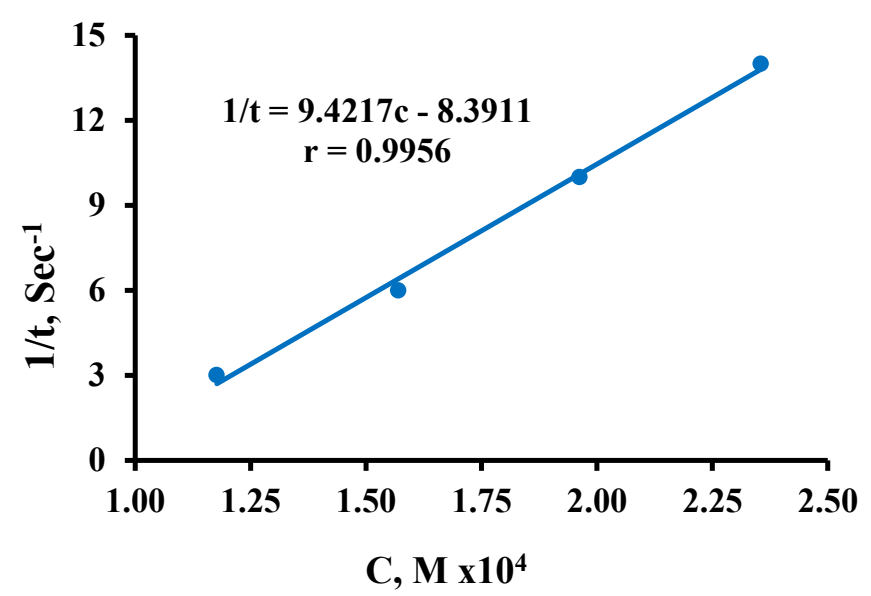

Figure 6. Calibration plot of $\mathrm{V}(\mathrm{V})$ for fixed absorbance method

\subsubsection{Fixed time method:}

At preselected fixed time, the absorbance of pink colored solution containing varying amounts of $\mathrm{V}(\mathrm{V})$ was measured at $25^{\circ} \mathrm{C}$ and $530 \mathrm{~nm}$. Calibration graphs were constructed by plotting the absorbance against the initial concentration of $\mathrm{V}(\mathrm{V})$ at fixed time $0-3600 \mathrm{Sec}(60 \mathrm{~min})$. The regression equations, correlation coefficients and linear ranges are given in (Table 1). It is clear that, the slope increases with the time and the most acceptable value of $\mathrm{r}$ was obtained for a fixed time of $2000 \mathrm{Sec}$ (Figure 7). Therefore, the fixed time of $2000 \mathrm{Sec}$ was utilized for assay of V(V) concentration.

Table 1. Regression equations for $\mathrm{V}(\mathrm{V})$ at fixed time and $25^{\circ} \mathrm{C}$.

\begin{tabular}{cccc}
\hline Time (Sec) & Regression equation & Correlation coefficient & Linear range (mg/L) \\
\hline 0 & $\mathrm{~A}=0.0093 \mathrm{C}-0.0056$ & 0.9982 & $2-12$ \\
500 & $\mathrm{~A}=0.0204 \mathrm{C}+0.0011$ & 0.9998 & $2-12$ \\
1000 & $\mathrm{~A}=0.0294 \mathrm{C}-0.0031$ & 0.9998 & $2-12$ \\
1500 & $\mathrm{~A}=0.0369 \mathrm{C}+0.0035$ & 0.9996 & $2-12$ \\
$\mathbf{2 0 0 0}$ & $\mathbf{A}=\mathbf{0 . 0 4 2 4 C}+\mathbf{0 . 0 0 7 4}$ & $\mathbf{0 . 9 9 9 9}$ & $\mathbf{2}-\mathbf{1 2}$ \\
2500 & $\mathrm{~A}=0.0445 \mathrm{C}+0.0113$ & 0.9997 & $2-12$ \\
3000 & $\mathrm{~A}=0.0463 \mathrm{C}+0.0125$ & 0.9997 & $2-12$ \\
3500 & $\mathrm{~A}=0.0468 \mathrm{C}+0.0194$ & 0.9993 & $2-12$ \\
\hline
\end{tabular}




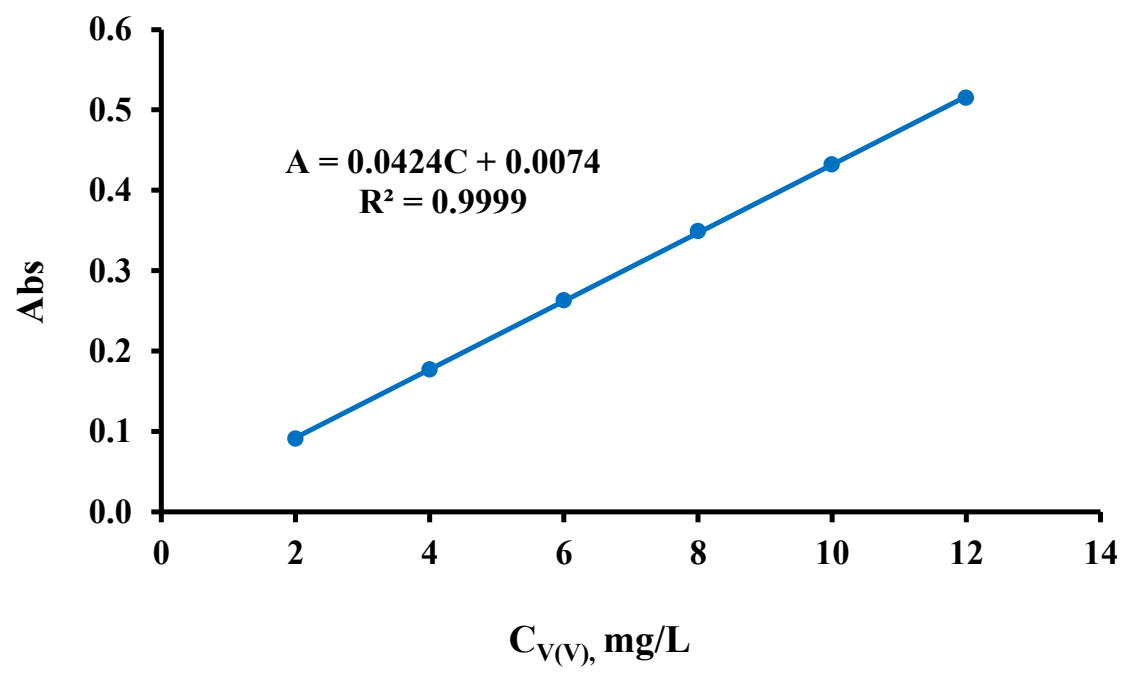

Figure 7. Calibration plot of V(V) for Fixed time method $(t=2000 \mathrm{Sec})$

\subsection{Analytical method validation}

\subsubsection{Calibration graph}

Correlation coefficient, intercept and slope values for the calibration data calculated using the least squares method [20]. It is clear that, both the slopes and intercepts increase with the time. The most acceptable values of the correlation coefficient of reaction products were obtained at 2000 Sec as fixed time, which was, chosen as the most suitable time interval for measurements (Table 2). After optimizing the reaction conditions, the fixed time method was applied to the determination of $\mathrm{V}(\mathrm{V})$ in crude oil and its heavy product over the concentration range of $2-12 \mathrm{mg} / \mathrm{L}$. The minimum level at which the investigated compound can be reliably detected (limit of detection, LOD) was determined experimentally for fixed time $(2000 \mathrm{Sec})$ method, was found to be $0.349 \mathrm{mg} / \mathrm{L}$.

Table 2. Analytical characteristics of the fixed time (2000 Sec) method.

\begin{tabular}{|c|c|}
\hline Parameters & $\mathbf{V}(\mathbf{V})$ \\
\hline$\lambda_{\max }(\mathrm{nm})$ & 530 \\
\hline Beer's law range $(\mathrm{mg} / \mathrm{L})$ & $2-12$ \\
\hline LOD $(\mathrm{mg} / \mathrm{L})$ & 0.349 \\
\hline Molar absorptivity $(\mathrm{L} / \mathrm{mol} \mathrm{cm})$ & $10^{4}$ \\
\hline formation constant & $1.66 \times 10^{3}$ \\
\hline Stoichiometric relationship, V(V):DPCI & $(1: 2)$ \\
\hline Regression equation $^{\mathrm{a}}$ & $\mathrm{A}=0.0424 \mathrm{C}+0.0074$ \\
\hline Correlation coefficient, $r$ & 0.9999 \\
\hline
\end{tabular}

${ }^{\mathrm{a}} A=m C+b$, where $A$ is the absorbance and $C$ is the concentration in $\mathrm{mg} / \mathrm{L}$.

\subsubsection{Accuracy and precision}

The accuracy and precision of the proposed method was carried out by three determinations at four different concentrations. Percentage relative standard deviation (RSD \%) as precision and percentage recovery as accuracy of the suggested method were calculated and showed in Table 3. The values of relative standard deviations for different concentrations of $\mathrm{V}(\mathrm{V})$ determined from the calibration curves. These results of accuracy and precision show that the proposed method has good repeatability and reproducibility. 
Table 3. Accuracy and precision for the determination of $V(V)$ in model samples taking from standards solution of $\mathrm{V}(\mathrm{V})$ ions.

\begin{tabular}{cccccc}
\hline & V(V), mg/L & & RSD \% & Confidence limit & \multirow{2}{*}{ Recovery \% } \\
\cline { 1 - 3 } Taken & Found $^{\mathbf{a}}$ & SD & & & \\
\hline 3.00 & 2.999 & 0.013 & 0.433 & $2.999 \mp 0.032$ & 99.96 \\
5.00 & 5.036 & 0.067 & 1.330 & $5.036 \mp 0.166$ & 100.72 \\
7.00 & 7.004 & 0.107 & 1.527 & $7.004 \mp 0.265$ & 100.05 \\
9.00 & 9.049 & 0.053 & 0.585 & $9.049 \mp 0.131$ & 100.54 \\
\hline
\end{tabular}

a Three independent analyses.

\subsubsection{Application to the Oil forms}

The average percent recoveries obtained, indicated good accuracy of the method. The result obtained for the analysis of the studied $\mathrm{V}(\mathrm{V})$ in oil forms was compared with those obtained with the Atomic Absorption method (Table 4). The proposed method is simple sensitive and reproducible and can be used for routine analysis of $\mathrm{V}(\mathrm{V})$ in model form and in oil forms. The proposed method was applied for determination of $\mathrm{V}(\mathrm{V})$ in crude oil and its heavy product. The results of analysis of the oil forms are shown in (Table 4).

Table 4. Determination of $\mathrm{V}(\mathrm{V})$ in crude oil and its heavy product by the proposed and Atomic Absorption methods.

\begin{tabular}{|c|c|c|c|c|}
\hline \multirow{2}{*}{ Nature of sample } & \multicolumn{2}{|c|}{$\begin{array}{c}\text { atomic absorption method } \\
\mathrm{n}=6, \propto=0.95\end{array}$} & \multicolumn{2}{|c|}{$\begin{array}{c}\text { proposed method } \\
\mathbf{n}=3, \propto=0.95\end{array}$} \\
\hline & RSD\% & $\bar{X} \overline{+} \Delta X(\mathbf{p p m})$ & RSD\% & $\bar{X} \overline{+} \Delta X(\mathbf{p p m})$ \\
\hline Light oil & 11.32 & $10.440 \mp 1.34$ & 1.150 & $9.739 \mp 0.28$ \\
\hline Heavy oil & 10.82 & $26.450 \mp 3.24$ & 0.827 & $24.276 \mp 0.50$ \\
\hline Fuel & 9.80 & $124.930 \mp 13.88$ & 0.292 & $123.601 \mp 0.90$ \\
\hline Coke & 9.09 & $734.070 \mp 75.62$ & 0.038 & $723.408 \mp 0.69$ \\
\hline
\end{tabular}

\section{4 - CONCLUSION}

The developed kinetic spectrophotometric method for the determination of $\mathrm{V}(\mathrm{V})$ was sensitive, accurate and precise and hence can be used for the routine analysis of V(V) in model oil and oil forms with a limit of detection of $0.349 \mathrm{mg} / \mathrm{L}$. The method was based on the reaction of V(V) with DPCI. The fixed time method for the proposed kinetic spectrophotometric method can be easily applied to the determination of $\mathrm{V}(\mathrm{V})$ in model oil and oil forms. The proposed method is compared with the previously reported method in terms of accuracy and precision. The proposed method is more selective and higher sensitivity than the sophisticated spectrophotometric techniques and similar reported methods.

\section{References}

[1] G. Goldstein, D.L. Manning, O. Menis, Spectrophotometric Methods for The Determination of Osmium-Ii, J. Talanta. 7 (1961) 301-306.

[2] S. Jaya. Y, T.V. Ramakrishna, Spectrophotometric Determination of Osmium with 1,5_Diphenylcarbazide, J. Talanta. 29 (1982) 619-622.

[3] A.R. Paniagua, M.D. Vazquez, M.L. Tascon, P.S. Batanero, Determination of Chromium(VI) and Chromium(III) by Using a Diphenylcarbazide-Modified Carbon Paste Electrode, J. Electro. Anal. 5 (1993) 155-163.

[4] L. Girard, J. Hubert, Speciation of Chromium (VI) and Total Chromium Determination in Welding Dust Samples by Flow-Injection Analysis Coupled to Atomic Absorption Spectrometry, J. Talanta. 43 (1996) 1965-1974. 
[5] M.J. Ahmed, S. Banoo, Spectrophotometric Method for Determination of Vanadium and Its Application To Industrial, Environmental, Biological And Soil Samples, J. Talanta. 48 (1999) 1085-1094.

[6] P. Rana, R. Lokhande, S. Pitale, S. Janwadkar, D. Yadav, Spectrophotometric Determination of Vanadium with Acetophenone 2', 4'-Dihydroxy Thiosemicarbazone, J. Chem. Tech. 6 (2014) 2295-2299.

[7] K. A. Kuliyev, N. A. Verdizade, Spectroscopic Investiqation Complex Formation of Vanadium Using 2,6-Dithiolphenol and Hydrofob Amins, J. Amer. Chem. 5 (2015) 10-18.

[8] B.V.N. Reddy, V.S. Basha, T.S. Reddy, Determination of titanium and Vanadium with 2,4Dihydroxy acetophenone isonicotinoylhydrazone by Direct and Derivative Spectrophotometric Method, J. Der. Pharma. Chemica, 7 (2015) 16-25.

[9] P.G. Chowdary, V.S. Basha, Determination of Vanadium in Different Environmental, Leafy Vegetable and Biological Samples Using 2-hydroxy-1-naphthaldehyde-p-hydroxy benzoichydrazone (HNHBH) Spectrophotometrically, J. Der. Pharma. Chemica, 7 (2015) 338345.

[10] B. Ranganath, L.K. Ravindranath, P. Venkataramana, Direct Spectrophotometric Determination of Vanadiu (V) Using 5- methoxy-2-[[(4-methoxy-3, 5-dimethyl-2-pyridinyl] methyl] sulfinyl]-1H-Benzimidazole [ESMPZL], J. Appl. Chem, 8 (2015) 60-64.

[11] K.H. Kadhim , Z.H. Hameed, Spectrophotometric Determination of Vanadium Using New Analytical Reagent 7-(6-bromo-2-benzothiazolylazo)-8- hydroxyquinoline, J. Iraqi. Chem, 56 (2014) 381-393.

[12] R. Gurkan, H.I. Ulusoy, A. Tamay, Speciative Determination of Total V And Dissolved Inorganic Vanadium Species in Environmental Waters by Catalytic-Kinetic Spectrophotometric Method, Arab. J. Chem, (2012). In Press.

[13] Q.Z. Zhai, X.X. Zhang, G. Huang, Kinetic-Spectrophotometric Determination of Trace Amounts of Vanadium(V) Based on Its Catalytic Effect on The Reaction of DBM-Arsenazo and Potassium Bromate, J. Spectrochim. Acta. 69 (2008) 911-916.

[14] M. Keyvanfard, Kinetic-Spectrophotometric Determination of Trace Amounts of Vanadium (V) Based on its Catalytic Effect on the Oxidation of Victoria Blue B by Potassium Bromate in Micellar Medium, J. World. Appl. Sci. 6 (2009) 624-629.

[15] R. Gurkan, O. Gurkan, Catalytic-Kinetic Spectrophotometric Determination of Vanadium (V) Based on Celestine Blue-Bromate-Vanadium (V)-Citric Acid Reaction, J. Rare. Metals. 30 (2011) 348-358.

[16] R.A. Hofstader, O.I. Milner, J.M. Runnels, Analysis of Petroleum for Trace Metals, Copyright, Advances in Chemistry Series, Forewor, J. Amer. Chen. Soc., Washington. D. C. USA. 156 (1976) 1-6.

[17] Trace Metals in Petroleum Products or Organics by AAS, Universal oil products (UOP) method (1995) 391.

[18] M. Kopanica,A.L. Et, Kinetic Methods in Chemical Analysis, J. Elsevier, Amsterdam, The Netherlands. (1983) 25-27.

[19] D. Pérsez-Bendito, M. Silva, Kinetic Methods in Analytical Chemistry, J. John Wiley and sons, New York (1988).

[20] Jn. Miller, Jc. Miller, Statistics and Chemometrics for Analytical Chemistry, J. Prentice Hall, England. (2005). 